\title{
Sujeito e mídia na autoficção literária e fílmica
}

Julia Scamparini; Instituto de Letras, Universidade Federal Fluminense - UFF, Niterói, RJ; E-mail: <juliascamparini@gmail.com>.

\section{Resumo}

A análise apresentada insere-se na perspectiva dos estudos em intermedialidade e é parte de uma investigação mais ampla sobre autoficções literárias e fílmicas. No romance Divórcio (Ricardo Lísias, 2013) e no documentário Histórias que contamos (Sarah Polley, 2012) constatam-se diversas dimensões de como vimos lidando com as novas (e velhas) tecnologias e as formas como os sujeitos vem se posicionando discursivamente com relação às e nas mídias literatura e cinema, refletindo sobre (e usando) a dupla palavra - imagem. $O$ sujeito que hoje "entra" na tela leva à investigação de como atualmente se pensa a escrita (registro, memória) pela palavra e pela imagem; como a mescla entre ficção e realidade se relaciona com o discurso da intimidade, próprio de obras autoficcionais; e como as novas possibilidades abertas para a atuação, troca, e invenção dos indivíduos deslocam a própria identidade do gênero (romance / documentário), bem como noções clássicas de recepção e análise a ele relacionados, abrindo espaço para o exercício da subjetividade.

Palavras-chave: autoficção, literatura, cinema documentário, subjetividade, palavra e imagem.

Diferente do que se convencionou chamar de autobiografia, a autoficção teve sua origem como gênero narrativo literário em 1977, na França, quando Serge Doubrovsky batizou seu romance Fils, uma mistura de ficção e biografia, de autoficção. Prática já bastante consolidada em seu país de origem, no Brasil a autoficção ganhou atenção e destaque inicialmente a partir do final dos anos 1980, quando escritores do calibre de Silviano Santiago adjetivaram suas obras de autoficcionais e pesquisadores da área de literatura passaram a dedicar-se ao fenômeno ${ }^{1}$. Apesar de passadas mais de três décadas, ainda

\footnotetext{
${ }^{1}$ Para um histórico do gênero, ver Hidalgo (2013).
} 
hoje o termo é controverso nas Letras e de pouco uso no Cinema $^{2}$, e vem aplicado neste trabalho ao que se costuma intitular documentário subjetivo ou autobiográfico, tais como os filmes Um passaporte Húngaro (Sandra Kogut, 2001), 33 (Kiko Goifman, 2003) e Santiago (João Moreira Salles, 2007), considerados precursores da tendência, e, no que se refere à literatura, a romances autoficcionais, tais como $O$ filho eterno (Cristóvão Tezza, 2007), Ribamar (José Castello, 2010) e $O$ céu dos suicidas (Ricardo Lísias, 2012).

Ainda que no cinema e na literatura sempre tenha havido obras que mesclam fatos conhecidos da vida do autor à invenção, o boom da autoficção no Brasil é contemporâneo à emergência da subjetividade da virada do século e à difusão da mídia digital, o que dá características inéditas à prática (Sibilia, 2008). Uma dessas características é, evidentemente, o falar de si, a exposição de fatos da vida pessoal ou familiar do autor da obra, seja ele escritor ou cineasta. Um "discurso do íntimo" que vem se materializando não somente em redes sociais ou afins, mas também em dispositivos como o cinema e a literatura, os quais pressupõem a existência de um autor para uma obra. $O$ fato de o autor duplicar-se na obra, por meio de nome ou fotograma, dilui uma distância pressuposta e esperada por quem a lê ou vê, produzindo um deslocamento que se configura como trabalho estético e, ao mesmo tempo, instaura um novo lugar de leitura, se partimos do conceito de pacto. $A$ quebra do pacto de leitura não é inofensiva porque equivale a uma quebra com relação a expectativas de realidade e de ficção, causando estranhamento a leitores de romances e documentários modernos e contemporâneos.

\footnotetext{
${ }^{2}$ Os poucos comentários e reflexões sobre autoficção no âmbito do cinema foram feitos por Jean-Claude Bernadet em seu blog outraspalavras.com.org/jcbernadet/.
} 
É por isso que filmes como Histórias que contamos (Sarah Polley, 2012) e livros como Divórcio (Ricardo Lísias, 2013) podem ser considerados autoficcionais, se assumirmos que 0 termo faz referência não somente à concordância entre autor e personagem, mas sobretudo à indefinição entre o que se entende a priori por real ou ficcional. Obras fílmicas e literárias unem-se no sentido de uma desordem do discurso sui generis, pois abordam o falar de si em uma época específica, em que romances, que pressupõem um contrato ficcional, fazem uso de elementos de real, e os documentários, tradicionalmente vinculados ao real, pressupondo um pacto documental, caracterizam-se por apresentar elementos ficcionais.

Sem discutir a fundo o estatuto desses dois regimes, concentramo-nos nas formas tal como vêm sendo combinados, de modo a refletir uma visão sobre a atualidade, no sentido do que faz Wolfgang Iser (2013) com sua antropologia literária, procurando entender os sentidos de fictício e imaginário a partir da natural disposição do homem para os mesmos. Assim, o que se apresenta nas autoficções é o real do trauma, irrepresentável, sobre o qual geralmente se cala (SeligmannSilva, 2013); e o ficcional das autoficções caracteriza-se como aquele que se aproxima ao imaginário, à memória, ao incorpóreo, muito mais do que o fictício da ficção, resultado de processos racionais de seleção e combinação (Iser, 2013). São, portanto, formulações de real e de ficcional essencialmente atravessadas por subjetividade.

\section{Sujeito, mídia}

Eu gostaria de dizer, antes de mais nada, qual foi o objetivo do meu trabalho nos últimos vinte anos. Não foi analisar o fenômeno do poder nem elaborar os fundamentos de tal análise. Meu objetivo, ao contrário, foi criar uma história dos diferentes modos pelos quais, em nossa cultura, os seres humanos tornam-se sujeitos. (Foucault, 1995: 231)

Em "O que é um autor?", Michel Foucault demonstra que o conceito de autoria não corresponde à referência de um indivíduo criativo portador de ideias e opiniões que escreveu 
determinado livro, mas sim a uma função que, para ser preenchida, exige que certas premissas sejam respondidas. Trata-se de uma operação que desloca o nome do escritor para uma esfera em que ele não mais designa a pessoa real, mas torna-se praticamente um título que reúne uma obra caracterizada por uma gama de qualidades, como estilo e coerência conceitual, e é reconhecidamente pertencente a tal autor. Este processo se dá a partir do momento em que o discurso literário se torna parte do sistema de propriedade que caracteriza nossa sociedade, tal como é também o fílmico: na medida em que os textos se transformaram de ato em produto, passaram a ter proprietários, de forma que, hoje, "o anonimato literário [e cinematográfico] não nos é suportável" (Foucault, 2006b: 276). Entre a autoria e o indivíduo designados por um mesmo nome próprio, não há, portanto, uma entidade una a qual se possa referenciar. Não obstante, a recepção de uma obra autoficcional nos leva inicialmente a unir duas ou mais posições subjetivas - autor/indivíduo/narrador -, e essa aparente simultaneidade de posições desdobra-se em novas formas de vivenciar o atrito entre real e ficcional.

Ao examinar as problemáticas que o gênero por si só apresenta, os enunciados e a configuração geral dos textos literários e fílmicos aqui estudados relacionam novos entendimentos acerca do sujeito contemporâneo e da memória, sendo que essa relação sujeito-memória se desdobra em reflexões que envolvem a mídia e o discurso.

Foucault (2008) entende por discurso uma dispersão regida por objetos, conceitos, estratégias e modalidades enunciativas, elementos que, reunidos por suas (ir)regularidades, delineiam formações discursivas. Por modalidades enunciativas Foucault entende o lugar, o status e os papéis que poderá assumir o sujeito que se servirá de um determinado discurso por compartilhar da ideologia a que ele se vincula. O sujeito aqui é tomado, portanto, como assujeitado, servo discursivo de suas filiações ideológicas e reificado pela dinâmica social e suas 
instituições, que se fundam pelos sistemas de dominação que colocam em prática, em determinada época.

Mas a noção de dispositivo, também foucaultiana, demonstra que o discurso é, na verdade, um dos modos através dos quais esses sistemas de dominação são colocados em vigor pelas instituições de poder e de governo. Conforme explica sinteticamente Courtine (2010: 29), "o discurso deve ser compreendido a partir daquilo que Foucault chama de dispositivo, isto é, um conjunto heterogêneo de instituições e de leis, de coisas e de ideias, de atos e de práticas, de falas e de textos, de dito e não dito".

As relações de poder e o governo dos outros são traços comuns da vida em comunidade, mas são noções naturalizadas comumente como negativas e pertencentes a regimes de governos autoritários ou totalitários. Nesse sentido, entendemos os sujeitos como peças do móbile manipulado pelas redes de dominação institucionais, responsáveis pelos ditos e não ditos sob os quais inevitavelmente organizamos nossa existência no mundo. Paradoxalmente, uma vez vivendo em regimes democráticos, compreendemo-nos como sujeitos livres.

Foucault argumenta que o que se deu no poder democrático moderno foi a adoção de um sistema de dominação por meio de mecanismos de sujeição - e não de exploração ou dominação, como em séculos anteriores. Assim, no interior mesmo da estrutura política que conhecemos como Estado, há uma astuciosa combinação de técnicas de individualização e de procedimentos de totalização baseados no "poder pastoral" (Foucault, 1995: 236 - 239), nascido com o cristianismo, mas que

ampliou-se subitamente por todo o corpo social: encontrou apoio numa multiplicidade de instituições. E, em vez de um poder pastoral e de um poder político mais ou menos ligados um ao outro, mais ou menos rivais, ha[via] uma 'tática' individualizante que caracteriza[va] uma série de poderes: da família, da medicina, da psiquiatria, da educação e dos empregados 
(idem: 238).

Diz-se individualizante porque, neste tipo de mecanismo de poder inclui-se o elemento liberdade, que garante aos sujeitos "um campo de possibilidades onde diversas condutas, diversas reações e diversos modos de comportamento podem acontecer" (idem: 244) - o que é totalmente oposto a um regime de escravidão, por exemplo. Ou seja, o paradoxo é lícito, pois fazemos parte de uma época em que somos livres dentro de um mecanismo de poder que nos assujeita.

Toda essa breve digressão pelos conceitos de discurso, dispositivo e poder é necessária para que possamos conhecer, através das práticas discursiva e institucionais, os mecanismos de sujeição em voga e através deles encontrar espaços de individualização através de práticas de liberdade. Seria como reconhecer o oponente para, na impossibilidade de vencê-lo, viver junto a ele da melhor forma possível. É um tipo de atitude que à primeira vista pode parecer de resignação, mas que na verdade é o que leva, através de práticas individuais de liberdade, a um possível processo de liberação (Foucault, 2012b).

O termo sujeito reúne, portanto, formas de assujeitamento bem como de singularização: mais do que uma modalidade enunciativa que inconscientemente se apropria de discursos, é também o posicionamento possível para o cuidado de si, para a inserção nas frestas abertas dos espaços discursivos disponíveis na contemporaneidade.

Tais espaços discursivos multiplicaram-se de forma incomparável na História. O discurso, ou o enunciado, "forma indefinidamente repetível e que pode dar lugar às enunciações mais dispersas" (Foucault, 2008), desdobra-se em uma variedade de materialidades, as quais devem ser tomadas a partir de suas especificidades, de modo a não nos voltarmos a elas ingenuamente. Assim, se pensamos nas especificidades das artes aqui estudadas, a literatura como dispositivo tradicionalmente envolve, além do discurso literário, o livro de 
papel, o suporte digital, a autoria, o sistema editorial e de bibliotecas, a crítica, a Academia, uma rede de conceitos, como o de "literariedade", entre tantos ditos e não ditos. Analogamente, o cinema como dispositivo envolve o discurso cinematográfico, a película, a autoria coletiva - simbolizada e institucionalizada pela figura do diretor -, as leis de incentivo, os festivais, a crítica, uma rede teórica própria, e a tecnologia digital.

Ao pensar em poder, encaminhamo-nos geralmente à observação dos sistemas de dominação e muito raramente às mídias, entendidas aqui inicialmente como objetos que fazem parte de uma rede discursiva. A poesia tornou-se algo a ser lido com a invenção da imprensa: tradicionalmente, poemas eram performados e, portanto, vistos e ouvidos; o filme era acessível apenas em salas de cinema até quando a televisão foi inventada, mudando nossos hábitos como espectadores; e quando a câmera Portapak foi disponibilizada, a possibilidade de o sujeito atuar como produtor de imagens em movimento fez emergir a videoarte. As mídias livro, TV e câmera evidentemente exercem um poder de outra natureza, que não passa necessariamente pelo conteúdo dos discursos, mas sim pela forma, o que nos direciona a novas experiências perceptivas e discursivas, como leitores e escritores de linguagens.

O conceito de mídia (meio, mediação) tomado pela Teoria da Mídia aproxima-se ao de dispositivo, e não somente porque hoje fazemos uma ligação quase que natural entre mídia massiva e poder. Por mídia entende-se tanto meio de comunicação de massa como suporte, sentidos comuns ao brasileiro, como meio, mediação ou rede (num sentido semelhante ao de dispositivo), acepções permitidas pelo alemão, língua do país em que teve início o media turn, a partir dos anos 1980 (Müller, 2012). Desta forma, tanto a literatura (dispositivo) como o livro (suporte) são mídias, e tanto o cinema como um filme também o são. Para entender a importância de se tomar as relações entre a arte e as mídias, 
podemos rememorar o célebre texto de Walter Benjamin, que relaciona a reprodutibilidade técnica a novas formas de percepção da arte e mesmo de nosso conceito de realidade, que desde então passa pela imagens técnicas. Por isso, segundo Müller (idem: 169):

Literatura e cinema devem ser entendidos como mídias
que se inter-relacionam de modos diversos, dentro de
um universo midiático bastante amplo, que inclui mídias
diversas, como a tradição oral, a canção popular, o rádio,
a imprensa escrita, a televisão, as artes visuais, a
internet, o videogame, etc. O estudo dessas inter-
relações configura o campo da intermedialidade. Teóricos da mídia chamam a atenção para o poder que a mídia por si só exerce sobre seus usuários, tal como a tipografia e a era da informação que com ela nasce, ou mesmo uma máquina fotográfica e sua tecnologia, que de antemão define cores, luz, padrões visuais que determinam um novo mundo, desenhado pelas imagens técnicas (Flusser, 2002). Para Machado (2005), a mídia digital produz novos sujeitos, fragmentados da mesma forma que a imagem é hoje fragmentada em pixels. No histórico que faz em seu estudo intitulado $O$ sujeito na tela, Machado examina como, a partir do cinema narrativo, outros sujeitos "entram" na tela, como aquele que nos "mostra" as histórias no cinema, ao mesmo tempo ignorado e assumido por todos os espectadores de filmes "transparentes" (Xavier, 2005), aqueles que não expõem ou abordam a linguagem cinematográfica como tema. Da película para a tecnologia analógica e, hoje, com a tecnologia digital, o audiovisual vai muito além do cinema, impondo novas formas de perceber e lidar com a imagem, estática ou em movimento, com a mente e o corpo - ainda que estejam tão naturalizadas em nossas vidas ao ponto de não notarmos sua onipresença: quando assumimos a identidade de um personagem de videogame, a relação sujeito-na-mídia fica evidente, mas ao digitar um texto também estamos lidando com a imagem técnica, o que demonstra uma grande mudança em nossa forma de convívio com o que vemos. 
Esta entrada do sujeito na imagem através das possibilidades digitais comporta, portanto, uma ruptura importante em nossas práticas de escrita, de leitura, e mesmo de estar no mundo. Essas rupturas impõem que analisemos as formas como os sujeitos estão atuando neste universo. Assumir que todo material verbal e discursivo passa pela imagem e pela rede (dispositivo, mídia) é o primeiro passo para examinar as malhas do discurso e nelas encontrar espaços de singularização.

Um encontro com a singularidade pode se dar, para o teórico do cinema Comolli (2008), no antes e depois de uma entrevista concedida, no registro de um backstage, numa fala acidentalmente gravada entre documentarista e documentado. Da forma como coloca, o documentário tal como o concebemos prototipicamente em nada acessaria o real, ou a realidade dos sujeitos retratados, pois somente nas fendas abertas entre a encenação é que se pode ter acesso ao autêntico, ao verdadeiro e ao subjetivo. Este exemplo é emblemático porque aponta para lugares do sujeito dentro das possibilidades da mídia e dos discursos a ela vinculados e por ela tomados, assim como as obras analisadas buscam fazer, como veremos.

Finalmente, o que chamamos "discurso do íntimo", temática colocada em pauta pelas obras analisadas, liga-se a discussões sobre o par público $x$ privado nascidas na filosofia $\mathrm{e}$ desdobradas por intelectuais de diversos campos de saber. Se ao invés da filosofia procedêssemos a uma análise arqueológica, veríamos que determinadas épocas lidaram com a intimidade de forma variada: os antigos, por exemplo, não tinham o conceito de privado que temos hoje, o que se desdobra no desconhecimento do que entendemos por íntimo, levando a cabo até mesmo a ideia de um discurso sobre a intimidade. Ao mesmo tempo, as práticas de cuidado de si eram mais comuns, seja como exame de consciência, escrita de si, correspondência, ou meditação. 
Apesar da mescla hoje inegável entre privado e público, ainda causa estranhamento enquadrar o íntimo em determinadas regras de formação discursiva, uma vez que há pouco tempo abordar a intimidade nos levava (e ainda leva) ao terreno do não-dito, da reserva que compartilhamos apenas com nossos botões. Arfuch (2010) defende que mais produtivo do que a crítica e o lamento que busca o retorno a uma divisão mais categórica entre lugares canônicos de privado e público é aceitar a ambiguidade atual e, a partir dela, empreender "uma reflexão mais atenta sobre a atualidade, sobre os modos cambiantes de expressão, manifestação e construção de sentidos" (idem: 96).

Assim, se hoje podemos falar em representações discursivas da intimidade, é porque o falar de si e do que entendemos como assunto privado tem se estabelecido como formação discursiva, fato marcante não somente nos novos espaços criados pelos canais midiáticos mais democráticos, como também na literatura e no cinema. Nesse sentido, fazer uso de um discurso sobre si através da narrativização de eventos biográficos ou familiares distancia-se do privado de uma forma contundente, a ponto de transformar um discurso considerado terapêutico ou umbiguista pela crítica em ato discursivo, ato político sobre a subjetividade contemporânea.

\section{Autoficção em livro}

Divórcio conta a história de uma separação traumática após 4 meses de casamento, rompimento que se torna inevitável depois que Ricardo Lísias, o narrador, lê o diário da esposa. Divórcio também é uma narrativa sobre o processo de escrita do romance homônimo, que reconstrói o processo de recuperação emocional do autor-personagem costurado a lembranças pessoais e familiares que o marcaram. É um livro sobre ética pessoal e profissional, e sobre a construção da memória através da escrita.

Ainda que tenhamos na história do romance a obra de Rousseau, pai da escrita autobiográfica, normalmente romance 
e autobiografia são tidos como gêneros distintos. Partindo do território do ficcional, que lhe é basilar, esta prosa de Lísias faz uso de signos que deslocam o leitor e a obra para um espaço biográfico, sem contudo colocar-se como biografia. O nome próprio do autor duplicado no personagem é o primeiro item de estranhamento, vinculação ao mundo real que se estabelece também por fotos e por declarações feitas em outros canais, acessíveis por um circuito discursivo-midiático que corrobora 0 incômodo gerado pelo romance: ainda que o autor afirme categoricamente que Divórcio é uma ficção, ele conversa com temas do livro, tais como a ética de uma classe de jornalistas, em entrevistas, depoimentos e redes sociais, e, ao fazê-lo, refere-se a fatos do livro tomando-os como realidade. Dentro e fora da obra os regimes de ficcionalidade ou realidade não são identificados.

Nesta mistura bastante atual entre ficção e real, a imagem entra no livro como ilustração, e principalmente como texto. Em alguns casos, uma fotografia vem separada por marcações tipográficas da mesma forma que pedaços de textos de um mesmo capítulo, o que nos faz ler a foto de modo diferente, interpretando-a conforme o já-lido mas também através de um desvendamento do que a foto faz ver, no que diz respeito a textura, signos, e também ambiente, época, estilo. Percebe-se, portanto, que a relação que o romance estabelece com o real passa por uma concepção de fotografia como documento, já que reconhecemos o Lísias autor quando criança, em um movimento análogo ao da doação do nome ao narrador, mas também como memória, uma vez que, ao que parece, o passado não é acessado (explicado) a não ser por meio de fotos (imaginado).

Lísias coloca em debate o conceito mesmo de documento, forçando ainda mais a provocação ao leitor com respeito à dinâmica entre palavra e imagem. As fotos em que ele não está presente podem ser de qualquer pessoa, mas, num primeiro momento e levados pela dedução, as assumimos como "verdadeiras", imagens dos avós do autor Ricardo Lísias, por 
exemplo. Nada prova a favor ou contra, mas o próprio romance acaba por induzir à reflexão sobre nossa relação com as imagens: assumimos que a fotografia é intrinsecamente documental, enquanto o próprio romance demonstra que podemos manipulá-la em diversos níveis, em favor do discurso desejado.

A palavra escrita também aparece em sua dupla utilidade documental e ficcional. É da leitura do diário da ex-mulher pelo narrador, cujos trechos aparecem repetidas vezes ao longo do romance, que se conhece a verdade sobre o casamento. Mas Lísias empreende aqui também um jogo ambíguo, pois tanto o diário da ex-mulher como o romance são textos que abordam o íntimo mais absoluto. No entanto, o romance, como parte do dispositivo literário, é materialidade de outra ordem, que permite que o discurso do íntimo seja abordado como tema. Lísias parece estar afirmando que, a serviço da memória, o uso que podemos fazer da palavra e da imagem é infinito.

Seu discurso do íntimo aborda os temas da sexualidade, da família, das drogas, dos afetos, o que inevitavelmente vincula uma obra como esta a produtos midiáticos baseados nesse tipo de exposição. A superposição das posições de autor, dada pelo entendimento do discurso como literatura, e de indivíduo, recuperada pelos índices referenciais nominal e imagético (restringindo-nos ainda ao objeto livro) deslocam a posição enunciativa do sujeito que fala de dentro do discurso da intimidade. A nosso ver, esta sobreposição de falantes estabelece uma dinâmica entre discurso do íntimo e mídia que vai além da ordem do sujeito e se esparrama pela própria mídia: se as entranhas desta "entidade" (não importa quem seja, real ou fictício) estão expostas, as entranhas da mídia a acompanham nessa exposição.

Temos, assim, um romance que conta a história de sua feitura, da relação entre autor e editor, que apresenta a intertextualidade em vida, e, principalmente, um romance que 
mostra a relação visceral entre quem escreve e o texto que se constrói:

(1) No sexto dia, com o corpo sem pele queimando apesar do frio, não me senti morto: tive certeza de ter enlouquecido. Eu acabara de escrever um SMS chamando minha mulher de puta quando, na metade de uma frase autobiográfica, achei que estava vivendo um dos meus contos.

Com certeza eu assinaria essa história (Lísicas, 2013: 15).

\section{Autoficção em filme}

Em um movimento direcionado a friccionar os regimes de realidade e ficção aguardados pelo espectador, documentaristas autobiográficos têm problematizado o uso da imagem como documento, do depoimento como verdade, e da performance e da encenação como artifícios, reiterando-os como elementos produtivos para o discurso cinematográfico de hoje, como no caso do filme de Sarah Polley.

Histórias que contamos é um documentário sobre a mãe da diretora, Diane Polley, que faleceu quando a filha era adolescente deixando um segredo pessoal e familiar. O filme aborda também o próprio processo de feitura, apresentando a investigação da diretora por meio de entrevistas a familiares e amigos, imagens de arquivo, entre performances e encenações. É um filme sobre narrativa e memória, sobre a versão que se constrói por cada sujeito que viveu uma história e a reconstrói através do discurso.

Nele vemos imagens encenadas, depoimentos pré-concebidos, situações de revelação performadas, ou seja, cenas ficcionais, as quais se revezam com imagens reconhecidamente documentais: cenas caseiras filmadas em super 8, depoimentos colhidos no ato da entrevista, gravações em estúdio - num cinema que não deixa de ser documentário mas que parece buscar sua expressão fundamental, deslocandonos para um lugar onde real e ficção não são opostos. O pacto referencial não é somente quebrado, mas alterna-se com o 
pacto ficcional, e é justamente essa impermanência que provoca o espectador a entender o que são as imagens que vê na tela, quem diz a verdade, quem foi - e sobretudo quem é, para os familiares - Diane Polley.

Sarah Polley não viveu muitos anos em companhia da mãe. E, na adolescência, descobriu que o homem que a criou não era seu pai biológico. Já adulta e cineasta, empreende esta busca pelos discursos que moldam a memória materna, tateando uma ausência que se corporifica pelas imagens recuperadas e pelas histórias construídas com o filme - ao mesmo tempo empreendendo uma reflexão sobre o papel da palavra e da imagem no desenho da memória, e definindo a subjetividade narrativa como tema central do filme.

A imagem serve a alguns propósitos: concordar com o que é dito, discordar do que é dito, complementar o que é (ou não é) lembrado. Produzidas em contexto familiar ou (re)criadas em estúdio, são costuradas de forma a se organizar conforme a narrativa que Polley vai criando, muitas vezes a despeito do que vai ouvindo.

Palavras de sentido muito próximo, aqui aplicamos o termo encenação (ou mise-en-scène) para as cenas que fazem referência ao passado da diretora, à época em que a mãe ainda era viva. Vemos imagens de duas mulheres que claramente representam Diane, e demoramos a perceber quais são reais, registradas no passado em tecnologia super 8 , e quais são encenadas para preencher lacunas imagéticas de momentos particulares da mãe, e momentos em família. As imagens documentais e as encenadas são indistintas, não há marca entre passado (sépia ou preto e branco) e presente, de forma que somente as figuras femininas diferenciam-se: 


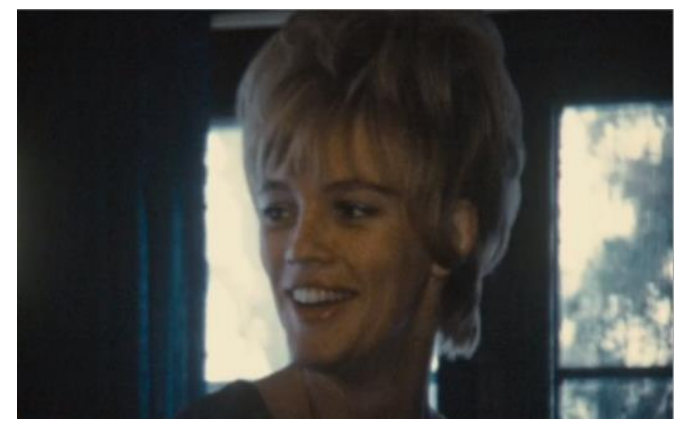

Fig.1: Diane Polley real (fotograma do filme Stories we tell)

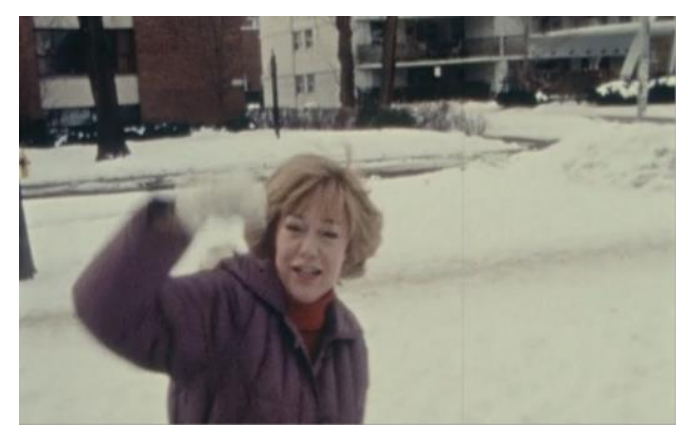

Fig. 2: Diane Polley fictícia (fotograma do filme Stories we tell)

As performances, por sua vez, referem-se aos momentos vivenciados para a câmera pela própria diretora-personagem, geralmente em companhia de um entrevistado, em que ela encena situações passadas (de revelação, no geral) como se estivessem ocorrendo sob o testemunho da câmera: temos a impressão de que ela descobre quem é o pai biológico em uma das entrevistas para o filme, o que se desfaz numa segunda visita à cena.

A palavra pronunciada pelo pai é o fio condutor da trama. Palavra dita, palavra escrita, palavra lida. Num exercício de exaustão, Sarah faz o pai lidar com sua própria história ao dar depoimentos, ao escrever sua versão dos fatos e ao ler seu texto, repetindo o já dito, numa renovação permitida pelo momento da enunciação. Sarah parece querer encontrar nas entrelinhas do discurso do pai uma resposta a uma pergunta que não conhecemos.

Gonçalo (2012) aponta para uma virada subjetiva no cinema brasileiro, iniciada por Eduardo Coutinho com Cabra marcado 
para morrer, e que, com novos traços, continua vigente. Segundo o pesquisador, o documentário subjetivo passou por fases: explorou com vigor a subjetividade do outro (Edifício Master), as vivências do autor (Santiago) e, mais recentemente, explorou o jogo com o espectador ( $O$ céu sobre os ombros). Eles, eu e tu permeados de uma subjetividade que já aponta para a defesa do imaginário como linguagem.

O autoficcional Histórias que contamos conjuga a vivência do autor e o jogo com o espectador. Da vivência do autor, destaca-se o discurso do íntimo, tomado pela visibilidade total permitida pela tecnologia digital. Do jogo, o estranhamento da quebra de contrato com o espectador, que, ao assistir um documentário, ainda espera encontrar uma verdade na narrativa, nas imagens, nos depoimentos, no gênero.

Assim, é legítimo falar de autoficção quando se pensa em filmes como este, porque está em jogo uma abordagem espaço-temporal que integra ficção e real de uma forma nova, que é subversiva e ao mesmo tempo remete ao cinema anterior a uma divisão de gêneros. Neste sentido, o termo autoficção remeteria a esse estranhamento causado pela quebra de fronteira entre ficção e real que desrespeita regras de gênero numa busca pelo outro, pelo que lhe é oposto. Não se trata de uma quebra completa do pacto esperado, conforme já acenado, mas de uma circularidade entre a quebra e o retorno ao pacto, deslocando o espectador continuamente entre um regime e outro. É justamente este deslocamento interno a um gênero que une obras literárias e cinematográficas sob o título de autoficção.

\section{O sujeito na mídia}

Esta análise parcial do romance Divórcio (2013), de Ricardo Lísias, e do documentário Histórias que contamos (2012), de Sarah Polley procurou descrever os efeitos que a presença do autor produz em romances e documentários autoficcionais, lugares em que o discurso do íntimo vai se desenhando como um discurso possível, que sai da ordem do não-dito para a 
ordem do dito. Estes resultados são parte de um trabalho de maiores proporções, que investiga as dinâmicas entre sujeito e mídia através de formações discursivas da contemporaneidade, tal qual a da intimidade.

Seria ingênuo afirmar que estas obras configuram escritas de si como técnicas de governo de si. Ao mesmo tempo, desconfiase do caráter terapêutico aproveitado por esses autores ao dissecar histórias pessoais através da arte, o que, contrariamente ao que se critica, consideramos válido. Através da dinâmica entre narrativas construídas por meio de palavras e imagens, por meio de lembranças escolhidas e desejos de memória, temos que conhecer as mídias - e aqui por mídia entendemos a própria imagem técnica assim como a palavra ou a literatura - para ter consciência de sua força atuando sobre nossas subjetividades. E, nesse sentido, nada mas autêntico ou verdadeiro do que confissões como as dessas obras - sejam elas reais ou não.

Com o foco no sujeito como objeto mais do que no sujeitoautor, este trabalho ainda busca respostas reunidas em três eixos:

- Que efeitos de sentido sobre o sujeito contemporâneo (assujeitado x singularizado) estão sendo produzidos com/por estas obras?

- Quais os efeitos de sentido sobre literatura e cinema (como dispositivos e como mídia) estes autores estão operando ao escolher o gênero da autoficção?

- Qual é o posicionamento discursivo acerca das representações da intimidade que se realiza com estas obras?

Ao empenhar-se na investigação histórica de como são compostas as maneiras de existir do sujeito, Foucault fez, em sua trajetória, diferentes apanhados: resgatou os gregos e suas 
práticas de cuidado de si, passou pela descrição e análise das sociedades disciplinares e atentou para a emergência histórica do Estado e de suas intervenções biopolíticas sobre o corpo do indivíduo e da população. O que parece estar acontecendo é um posicionamento dos autores em relação tanto ao lugar do autor como ao lugar do indivíduo, massacrado pelos dispositivos de controle e, ao mesmo tempo, pelas leis da comunicação total. Um indivíduo que tem que entrar nas malhas da mídia para um tentativa de controlá-la, e que tem que entrar nas malhas de um discurso que, antes pertencente à ordem do não-dito, era menos subjugado ao sistema. Um indivíduo que usa a mídia para o cuidado de si, fazendo a escrita de si, para proceder a um processo de singularização:

\footnotetext{
O que chamo de processos de singularização é algo que frustra esses mecanismos de interiorização dos valores capitalísticos, algo que pode conduzir à afirmação de valores num registro particular, independentemente das escalas de valor que nos cercam e espreitam por todos os lados (Guattari \& Rolnik, 1996: 47).
}

Os possíveis interpretáveis são muitos, mas um deles nos parece que não excluirá nenhum outro: o fato de essas obras se configurarem como atos discursivos muito mais do que produtos culturais subjugados a um sistema de propriedade ainda que façam parte dele. E outro possível interpretativo não excludente é que também um ato político desses livros e filmes sobre experiências tão pessoais pode ser identificado na exposição discursiva do trauma, no mostrar e falar sobre o que comumente se que esconder: minha mãe fez um filho fora do casamento, minha mulher me traiu. Trata-se de um ato político que se limita à esfera dos afetos mais íntimos, dos discursos que raramente ganham voz, mas que cada vez mais fazem parte de um posicionamento subjetivo do século XXI.

\section{Referências}

Arfuch, L. (2010). O espaço biográfico: dilemas da subjetividade contemporânea. Rio de Janeiro: EdUERJ. 
Comolli, J-L. (2008). Sob o risco do real. In: Ver e poder - A inocência perdida: cinema, televisão, documentário. Belo Horizonte: Editora UFMG.

Courtine, J-J. (2010). Discurso, história e arqueologia. In: Milanez, N. e Gaspar, N. R. (orgs). A (des)ordem do discurso. São Paulo: Contexto.

Flusser, V. (2002). Filosofia da caixa preta. São Paulo: Relume Dumará.

Foucault, M. (2006a). Isto não é um cachimbo. In: Motta, M.B. (org). Estética: Literatura e pintura, música e cinema. Coleção Ditos \& Escritos III. Rio de Janeiro: Forense universitária.

. (2006b). O que é um autor? In: Motta, M.B. (org). Estética: Literatura e pintura, música e cinema. Coleção Ditos \& Escritos III. Rio de Janeiro: Forense Universitária.

. (2012a). A escrita de si. In: Motta, M.B. (org). Ética, sexualidade e política. Coleção Ditos \& Escritos V. Rio de Janeiro, Forense Universitária.

- (2012b). A ética do cuidado de si como prática de liberdade.. In: MOTTA, M.B. (org). Ética, sexualidade e política. Coleção Ditos \& Escritos V. Rio de Janeiro, Forense Universitária.

. (2012c). Uma estética da existência. In: Motta, M.B. (org). Ética, sexualidade e política. Coleção Ditos \& Escritos V. Rio de Janeiro, Forense Universitária.

. (2012d). Verdade, poder e si mesmo. In: Motta, M.B. (org). Ética, sexualidade e política. Coleção Ditos \& Escritos V. Rio de Janeiro, Forense Universitária.

(2008). A arqueologia do saber. Rio de Janeiro: Forense universitária.

. (1995). O sujeito e o poder. In: Dreyfus, H. \& Rabinow,

P. Michel Foucault, uma trajetória filosófica: para além do estruturalismo e da hermenêutica. Rio de Janeiro: Forense Universitária.

Gonçalo, P. (2012). The subjective turn in Brazilian documentaries. In: Congress of the Latin American Studies Association, 201, San Francisco, California. USA. Retrieved from: https://www.academia.edu/3350002/The_subjective_turn_in_Brazilian _Documentaries 
Guattari, F. \& Rolnik, S. (1996). Micropolítica: cartografias do desejo. Petrópolis: Vozes.

Hidalgo, L. (2013). A imposição do eu. In: Rascunho. Disponível em: http://rascunho.gazetadopovo.com.br/autor/luciana-hidalgo/

Iser, W. (2013). O fictício e o imaginário. Rio de Janeiro: EdUERJ.

Lejeune, P. (2008). O pacto autobiográfico: de Rousseau à internet. Belo Horizonte: Editora da UFMG.

Lísias, R. (2013). Divórcio. São Paulo: Alfaguara.

Machado, A. (2007). O sujeito na tela: modos de enunciação no cinema e no ciberespaço. São Paulo: Paulus.

Müller, A. (2012). Linhas Imaginárias: poesia, mídia, cinema. Porto Alegre: Sulina.

Müller, A. \& Scamparini, J. (2013). Muito além da adaptação: literatura, cinema e outras artes. Rio de Janeiro: 7Letras.

Scamparini, J. (2013). "Presença do autor: autoficções de Ricardo Lísias e de Lúcia Murat”. Revista Itinerários, Araraquara, n. 36, p.277286. Disponível em: http://seer.fclar.unesp.br/ itinerarios/article/view/5694/4723

Seligmann-Silva, M. (org). (2013). História, memória, literatura. Campinas: Ed. da Unicamp.

Sibilia, P. (2008). O show do eu: a intimidade como espetáculo. Rio de Janeiro: Nova Fronteira.

Stories we tell (Histórias que contamos). (2012). Direção e roteiro: Sarah Polley. Documentário. Canadá. [DVD]. (108 min), colorido.

Xavier, I. (2005). O discurso cinematográfico: a opacidade e a transparência. São Paulo: Paz e terra. 